\title{
cDNA Cloning and Sequence Analysis of a Novel Calcium Binding Protein with Oligoproline Motif
}

\author{
Su Yu ${ }^{1}$, Masayuki Ozawa ${ }^{1}$, Apala Farhat Naved ${ }^{1}$, Teruo Miyauchi ${ }^{2}$, Hisako Muramatsu ${ }^{1,3}$, and \\ Takashi Muramatsu1,3,† \\ ${ }^{1}$ Department of Biochemistry, Faculty of Medicine, Kagoshima University, 8-35-1 Sakuragaoka, Kagoshima \\ 890, ${ }^{2}$ Japan Immunoresearch Laboratories, 351-1 Nishiyokotemachi, Takasaki, Gumma 370, and ${ }^{3}$ Department \\ of Biochemistry, Nagoya University School of Medicine, 65 Tsurumaicho, Showaku, Nagoya 466, Japan
}

Key words: Calcium binding protein/lectin binding site/oligoproline/Src homology region III

\begin{abstract}
$A B S T R A C T$. Using antibodies against pokeweed agglutinin-binding proteins from F9 embryonal carcinoma cells, we isolated a cDNA clone PW29 reacting with the antibody. mRNA hybridizing with the cDNA was 4.7 kb, and was strongly expressed in the testis, brain, kidney and heart as well as in F9 cells. The size of mRNA in the testis was heterogeneous. Sequencing the cDNA clone revealed a putative polypeptide of $70 \mathrm{kDa}$, which is rich in hydrophilic amino acids and has a characteristic sequence of (GluLys) 5 . The protein also has an oligoproline motif, which conforms to the rule of binding capability to Src homology region III. The cDNA was translated as a fusion protein with glutathione-S-transferase, and was verified to have calcium binding activity, upon a calcium blot experiment.
\end{abstract}

Calcium binding proteins play important roles in regulation of cellular activities. They are classified into two groups; those with so-called EF-hand motif $(4,5)$ and those without it. An example of the latter is calreticulin, which is a calcium binding protein in endoplasmic reticulum (7). Calreticulin has segments rich in acidic amino acids or rich in acidic amino acids and proline, which serve as calcium binding sites (1). This paper describes a novel calcium binding protein, which lacks EF-hand motif, and is present in embryonal carcinoma cells. A novel calcium binding protein with EF-hand motif (12) and the one without it (10) were previously found by us also in embryonal carcinoma cells.

\section{MATERIALS AND METHODS}

Immunoscreening of an expression library. Glycoproteins which bind to pokeweed agglutinin (PWA)-agarose were isolated from F9 embryonal carcinoma cells grown subcutaneously in 129/slcp mice as described previously (9). Rabbit antiserum against the PWA-binding glycoproteins were produced (10), and was absorbed by disrupted Escherichia coli Y1090, and used to screen $\lambda \mathrm{gt} 11$ cDNA library as described by Schuh

\footnotetext{
${ }^{\dagger}$ To whom correspondence should be addressed.

Abbreviations: G buffer; $50 \mathrm{mM}$ Tris- $\mathrm{HCl}$ buffer, pH 9.6 containing $5 \mathrm{mM}$ glutathione, GST; glutathione S-transferase, MBP; maltose binding protein, $\mathrm{PBS}(-)$; Dulbecco's phosphate buffered saline without $\mathrm{Ca}^{2+}$ and $\mathrm{Mg}^{2+}$; PWA; pokeweed agglutinin, $\mathrm{SSC} ; 0.15 \mathrm{M} \mathrm{NaCl}$, $0.015 \mathrm{M}$ sodium citrate.
}

et al. (14). The library, constructed from mRNAs of F9 embryonal carcinoma cells, has been described (8).

Plaque screening. Approximately $1 \times 10^{6}$ phages were screened according to Benton and Davis (2) with EcoRI/XhoI fragment of PW29 cDNA (one of the positive clones obtained from $\lambda \mathrm{gt} 11 \mathrm{cDNA}$ library) as the hybridization probe. Filters were hybridized overnight at $42^{\circ} \mathrm{C}$ in hybridization solution containing $50 \%$ formamide, $5 \times \mathrm{SSC}$, $50 \mathrm{mM}$ sodium phosphate buffer $\mathrm{pH} 6.5,10 \times$ Denhardt's solution, $0.1 \%$ SDS, and $100 \mathrm{mg} / \mathrm{ml}$ heat-denatured salmon sperm DNA. The filters were washed twice with several changes of $2 \times \mathrm{SSC}$, $0.1 \%$ SDS at room temperature followed by several washes in $0.1 \% \times \mathrm{SSC}, 0.1 \% \mathrm{SDS}$ at $55^{\circ} \mathrm{C}$. Phage DNAs were isolated by plate lysis (6).

Subcloning and DNA sequencing. Phage DNA from positive clones were digested with $E c o R I$, and the cDNA inserts were subcloned into the EcoRI site of plasmid vector pUC18. The inserts were further digested with various restriction enzymes, and the resulting fragments were subcloned into the plasmid vector pUC18 or pBluescript II (KS+). DNA nucleotide sequences of the fragments were determined by the dideoxy chain-termination method (13). Homology was searched by the program of Software Development, Tokyo, employing the data base of EMBL-GDB, LASL-GDB (GenBank) and NBRF-PDB.

RNA analysis. Total cellular RNA and total RNA from tissues were extracted by the acid guanidinium thiocyanatephenol chloroform method (3). RNA was denatured with glyoxal, separated on a $1 \%$ agarose gel and transferred to ni- 
trocellulose membrane in $20 \times \mathrm{SSC}$. The membrane was baked for $2 \mathrm{~h}$ under vacuum at $80^{\circ} \mathrm{C}$ and treated in $20 \mathrm{mM}$ Tris- $\mathrm{HCl}$ buffer, $\mathrm{pH} 8.0$ at $100^{\circ} \mathrm{C}$ for $5 \mathrm{~min}$. RNA blots were prehybridized for $2 \mathrm{~h}$ in $50 \%$ formamide, $50 \mathrm{mM}$ sodium phosphate, pH $6.5,200 \mu \mathrm{g} / \mathrm{ml}$ heat denatured salmon sperm DNA, $10 \times$ Denhardt's solution and $1 \%$ SDS at $42^{\circ} \mathrm{C}$ and hybridized for $20 \mathrm{~h}$ with $\left[\alpha{ }^{32} \mathrm{P}\right]-\mathrm{dCTP}-$ labeled cDNA probes prepared by a random hexanucleotide priming method, at $0.5-2.0 \times 10^{7} \mathrm{cpm}$ $/ \mathrm{ml}$ under conditions identical to those used for prehybridization. The washing conditions of the membrane were the same as plaque hybridization. As a control, mouse $\beta$-actin cDNA was used.

Preparation of fusion proteins. For producing maltose binding protein fusion protein (MBP-PW29), EcoRI fragment of PW29 was subcloned into a MBP fusion protein vector, pMAL-c (Bio-Labs.). E. coli TB1 cells were transformed with the recombinant plasmid, which encodes the fusion protein. The cells were cultured, induced for fusion protein production, and collected according to the protocol of the producer (Bio-Labs.). The collected cell pellet was suspended in Dulbecco's phosphate-buffered saline without $\mathrm{Ca}^{2+}$ and $\mathrm{Mg}^{2+}$ $[\mathrm{PBS}(-)]$ and disrupted by sonication. After centrifugation of the sonicate at $12,000 \mathrm{rpm}$ for $30 \mathrm{~min}$, the supernatant was applied to a column of amylose-resin (Bio-Labs.) (column volume $=1 \mathrm{ml}$ ), and the column was washed with 5-10 column volumes of $\mathrm{PBS}(-)$ containing 1\% Tween 20 and with PBS $(-)$ successively. The fusion protein was eluted with 10 $\mathrm{mM}$ maltose in PBS( - ). About $5 \mathrm{mg}$ of fusion protein was obtained from 1 liter of bacteria culture suspension.

For producing glutathione-S-transferase (GST) fusion protein, plasmid PW29 was digested with AatII, blunt-ended with T4 DNA polymerase, and then subcloned into SmaI site of glutathione-S-trans-ferase fusion protein vector, pGEX-
2T. JM109 cells were transformed with the recombinant plasmid, which encodes the fusion protein. Forty-five ml of LB medium were inoculated with $5 \mathrm{ml}$ of an overnight culture and allowed to grow to an OD of 1.0. Isopropylthio- $\beta$-D-galactoside was added to a final concentration of $1 \mathrm{mM}$, and the cultures were allowed to grow a further $6 \mathrm{~h}$ at $37^{\circ} \mathrm{C}$. Cells were then pelleted, resuspended in $5 \mathrm{ml}$ lysis buffer [50 mM Tris$\mathrm{HCl}, \mathrm{pH} 7.5$, containing $25 \%$ sucrose $0.5 \%$ Nonidet $\mathrm{P}-40$ and $5 \mathrm{mM} \mathrm{MgCl}_{2}$ ]. After sonication, debris was pelleted by centrifugation for $15 \mathrm{~min}$ at $12,000 \mathrm{rpm}$. The supernatant was applied to a glutathione-agarose column $(1 \mathrm{ml})$. Following three washes with $3 \mathrm{ml}$ washing buffer [ $20 \mathrm{mM}$ Tris- $\mathrm{HCl}, \mathrm{pH} 7.5$, containing $2 \mathrm{mM} \mathrm{MgCl}_{2}$ and $1 \mathrm{mM}$ dithiothreitol], the protein was eluted from the column with $3 \mathrm{ml}$ of $\mathrm{G}$ buffer [50 mM Tris- $\mathrm{HCl}$, pH 9.6 containing $5 \mathrm{mM}$ glutathione]. Alternatively, pelleted cells grown in 1 liter of LB medium were resuspended in $100 \mathrm{ml}$ of the lysis buffer, sonicated, and centrifuged at 10,000 rpm for $20 \mathrm{~min}$. The supernatant was applied to $14 \mathrm{ml}$ of glutathione-agarose column, followed by washing with $70 \mathrm{ml}$ of washing buffer. Fusion protein was eluted by washing with $30 \mathrm{ml}$ of $\mathrm{G}$ buffer as described previously. From 1 liter of bacterial culture, about $40 \mathrm{mg}$ of fusion protein was obtained.

Preparation of anti-fusion protein antibodies. AntiMBP-PW29 fusion protein antibodies were prepared as follows. MBP-PW29 fusion protein $(50 \mu \mathrm{g})$, which was purified as described before, was emulsified with an equal volume of Freund's complete adjuvant. New Zealand White rabbits were immunized subcutaneously with the emulsion. After four booster injections at two-week intervals using the same amount of the antigen, the rabbits were bled and antisera were obtained.

Calcium blot. Glutathione-S-transferase $(5 \mu \mathrm{g})$ and gluta-

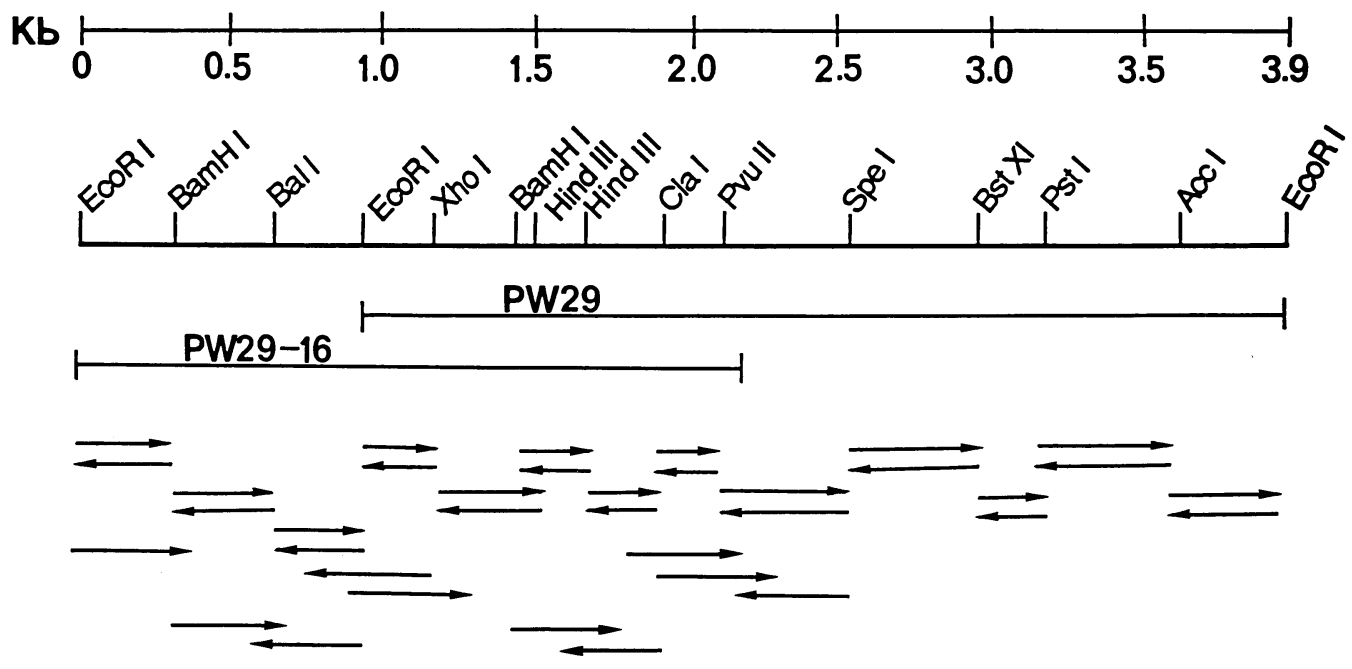

Fig. 1. Restriction endonuclease map and sequencing strategy for the PW29 cDNA clones. The scale indicates nucleotide positions (in kilobase) beginning from the first base of the cDNA. The PW29 and extended PW29-16 cDNAs were shown under the scale. The endonuclease sites indicates above these two line were used to generate cDNA fragments for sequencing. The arrows illustrate the direction and extent of DNA sequences obtained in each experiment. 
thione-S-transfearse-PW29 fusion protein $(5 \mu \mathrm{g})$ were electrophoresed on $10 \%$ SDS-PAGE and were transferred to a nitrocellulose membrane. After washing the membrane with solution A $(60 \mathrm{mM} \mathrm{KCl}, 5 \mathrm{mM} \mathrm{MgCl}, 10 \mathrm{mM}$ imidazole- $\mathrm{HCl}$,
$\mathrm{pH}$ 6.8) two to three times in $1 \mathrm{~h}$, the membrane was then incubated with solution A containing ${ }^{45} \mathrm{Ca}(10 \mu \mathrm{Ci} / \mu \mathrm{g}$; New England Nuclear) at $1 \mu \mathrm{Ci} / \mathrm{ml}$ for $10 \mathrm{~min}$, rinsed with distilled water, dried, and then exposured to X-ray film for $24 \mathrm{~h}$. The

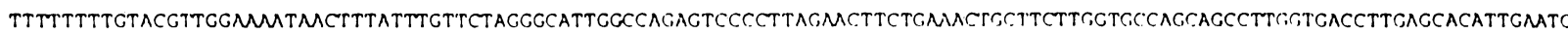
GCACACTCTTGCTCAGGGTCCTCCACTCTCCAACTGTCACAATCTCTCCCATCTG'IACATCCCTGALACAGCCGCACAGGTGCACAGACATGTTCTTC'RGACGCTTCTCAAAGCGATTCT ACTTTCGGATGTAATGGAGATAGTCCCGGCGGATCACAATGCTCCTCTGCATCTTCATCT'ГCGTCACCACACCACACAGGATCCGACCTCCGATGGAGACGTTACCAGTGAAGGGGCATT TCTTGTCTATGTAGGTACCCTCAATAGCCTCTTTAGCCGTCTTCAAGCCTACACCGATATTCTTGTAGTACCGAGGGAGTTTTTCCTTGCCGGTTTCTCCCAGCAGAACCCGCTTCTTGT TTTGAAAGATCGTAGGCTCCTTTTGGTAAGCACGCTCCGTCTCAATCTCCGCCATCTTCCTTCTTATTTCATAGCANATAAGMAMATCT

ATGTTCTACGCACATTTTCTCCTCAGTAACGAGGGCCTCTGGCCAMATCTGGCTGGCGGCCCATTGGGACAAGMGCTAACCANAGCCCATGTATTIGAGTGCAACTTAGAGAGCAGT 6B

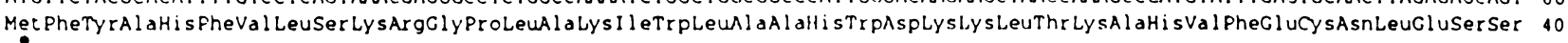
GTGGAGAGCATCATCTCACCAMAGGTCMGATGGCGCTGCGGACGTCAGGACACCTTCTCCTCGGAGTAGTCCGCATCTATCACAGCMAGCCMNATACCTCCTCGCAGACTCTALTGM BO

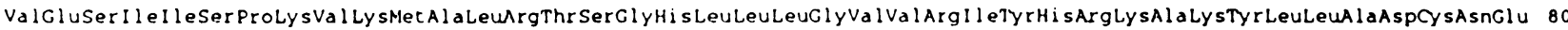

GCATTTATTALAATAAAGATGGCGTTTCGGCCAGGTGTTCTCGATCTACCTGAGGAMMTCGGGAGCAGCTTATAATGCCATTACTTTACCTGAGGAATTCCACGATTTTCATCAGCCA 926

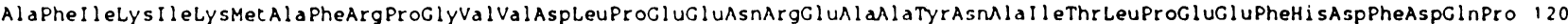

CTGCCAGATTTAGATGATATTGACGTCGCCCAGCAGTTCAGCCTGMACCAMGCAGAGTAGMGAGATAACCATGAGAGAGAAGTCGGAACATCAGTATCCTACAGGANAATGACTTT IO 46

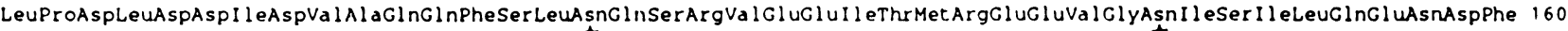

GGTCACTTCGGAATGGATGACCGTGANATAMTGAGAGAMGCAGTGCTTTCGAGGATCACGACATCTTAGTGAGCACCAGCGCTTCCMCCTTCTCCTCGAGCCAGAGCAGAGCACCAGC II 66

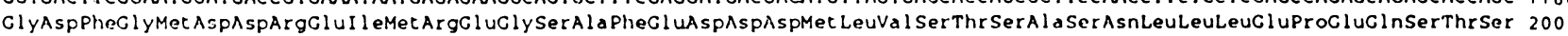

AACCTGAATGAANAGATGAATCACTTAGAGTACGAAGACCAGTACAAAGATGACAATTTTGGACAAGGAAATGATGGCGGTATATTAGATGACAAACTTATAAGTAATAATGATGGTGGC I28

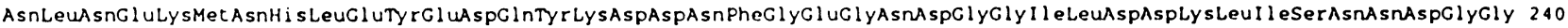

ATCTTTGACGATCCCCCTGCCTTGTCTGAGGCAGGGGTCATGTTGCCAGAGCANCCTGCACATCATCACATGGATGNAGATCACAATGGCTCACTGGGTCGGCCGGATAGTCCCGACTCT I 06 Il ePheAspAspProProAlaLeUSerGlUAlaGlyValMet LeuProGluGInProAlaHI sAspAspMetAspGIUAspAspAsnGlySerLeuGlyGlyProAspSerProAspSer 280 GTGGATCCTGTCGAACCGATCCCAACTATGACTGATCAGACAACTCTCGTCCCANACGAGCAACAACCTTTTTCCGTTGGAGCCCATTGATATMCTGTCMAGAGACAAAAGCCMGAGG 1526

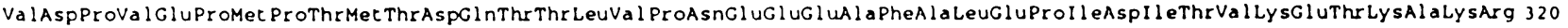

AAGAGGAAGCTGATTGTTGACAGTGTCAAAGAATTGGATAGTAAGACCATTAGAGCCCAGCTTAGCGATTATTCTCATATTCTTACGACTCTGGACCTGGCTCCGCCAACCAAGMAGCTT 1646

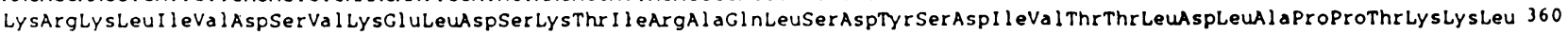

ATCATCTGGAAGAGACAGGAGGAGTCGAANAGCTCTTCTCCTTACCAGCACAGCCCCTGTGGAATAACCGGCTACTGAAGTCTTCACACGCTGCCTTACCCCACTTGTACCAGAGAC 766

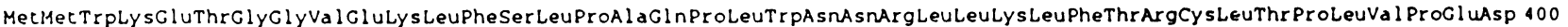

CTTAGGAAGAGAAGCAAAGGGGGAGAGGCAGATAATCTGGATGAGTTCCTCAAAGAGTTTGAGAATCCAGAGGTTCCCAGAGAGGAGCAGCAGCCACAGCAGCAGCAGCCACAGCCGCAG 18 B 6

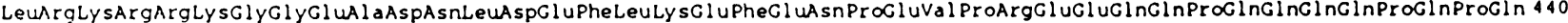

CGAGATCTCATCGATGAGCCCATTATAGAAGAGCCAAGCCGCCTCCAGGACTCAGTCATGGAGCCCAGCAGAACAACCATAGAAGAATCAGCCATCCCCCCACCACCCCCTCAAGGAGT 2006

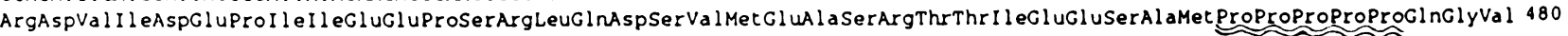

AAGCGGAAACCCGGGCAAATAGACCCAGAGCCTTCGATACCTCCTCAGCAGGTAGAGCAAATGGAAATACCACCAGTACAACTTCCCCCAGAGGAGCCTCCAAATATCTCTCAGCTGATC 2126

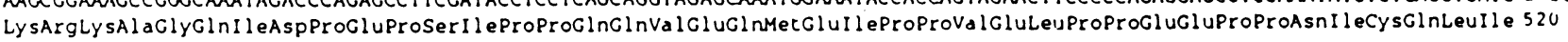

CCGGAGTTAGAGCTCCTACCGGAGAAGGAGAGGGAAAAGAGAAGGAGAAGGAAGAGGAGGAGGAGGAGGAGGATGAAGATGCTTCAGGGGGTGATCAGGATCAAGAGGAAMGGAGATGG 2246

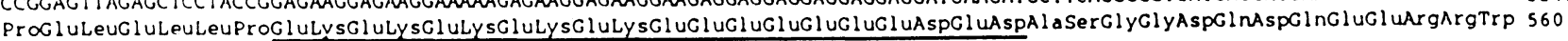

AACAAACGCACTCAGCAGATGCTTCATGGTCTTCAGCGAGCTCTTGCTAAAACTGGAGCAGAGTCTATCAGTTTGCTTGAGCTGTGTCGAAACACAAACCGAMGCAGGCAGCAGCAAAG 2366

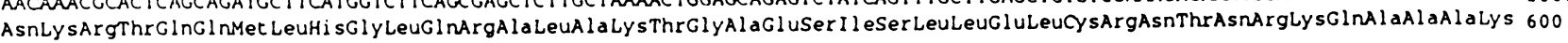

TTCTACAGCTTTTTGGTTCTTAAGAAGCAGCAAGCCATCGAGCTCACACAGGAAGAGCCGTACAGTGACATCATTGCAACCCCTGGACCACGGTTCCATATTATCTGA

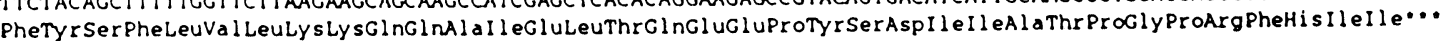

TCAGCTAGATGTGTTCGAGCTAGTGATAACTCACTAGTACATACAAATTGCCCCCGTGTGCAGGGCACCAAAACCCTTTAAGAAAGTTTTTAGATTTCTCTTTGTACAAAAATCTTTGCC TCAGCTAGATGTGTTCGAGCTACTGATAACTCACTACTACATACAAATTCCCCCCCTOTGCACCGCACCATTGGGTTGGGTTTCTATTCCTGGAGAAAACAGTAGCCCAAGAACCCAGAAG

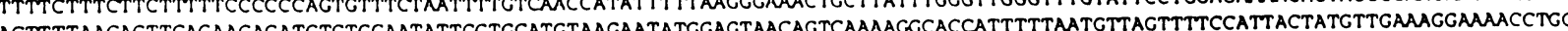

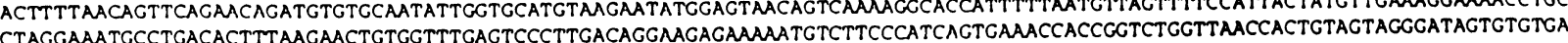

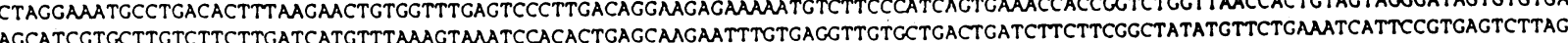
GACCTCTGATGCATGCACCCCAGCTCAGAACGATCAGACGTCTACCGTGGCGTGACTCCTCAGGGGCTGCAGATCACTCTCACAGGTGTTTGGATGTTTGCTTGAATAATCAGATCATGC GACCTCTCATGCATCCACCCCAGCTCAGAACGATCAGACGTCTACCGTGGCGTCACTCCTCAGCGGCTGCAGATCACTCTCACAGGTGTTGGATGTTTCTCTGATATTATTATAAATGTT AAGCAGACATTCCCCTCCCTGCTGAAGGGCAGACCAATGAGAGACTACCCCAGATTCACTTCCTTT TAGCAAACAGTCCTGTAUAACTAATGGCTTCTCTGATATTATTATAUTCTTA GTACTCATCTTTTTCCAAGGCTGCACACTCCTGTATTGCAACTTATTTTTAATMACTTTGCAACTATAATCCTGTATCAGTTTCCTATAATTTAAGTGGAGAAALACATCCTAATAAAGC CTTATTATT ACAGACCAGATGCACCAGATTATGTGACTATATAATATCAAAAGATGTTCACTTGTAGGACAAAATTATGTTCAAAACTTCTAGCTTAAGTGTTCGCACTTTTAGGGG GCGGAAATCAGTTTTAAAACTA GACTTCCATCTCGACGTATACCCACTAATTTAAAATTATGTGAAATATTTTAAATATTTTAAATTTCTGAACTCGTAATACTACTTTAATCATTCAC GCGCAAATCAGTTTTAAAACTAMGACTTCCATCTCGACGTATACCCAGTAATTTAAAATTATGTCAAATATTTTAAATATT TTAATTGTAAAAGACACTGTAGATAATTCAATGTTTGATTA

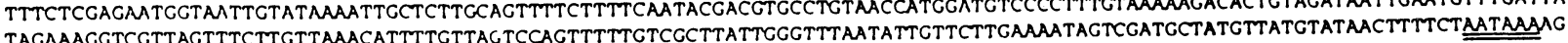
TAGMAAGGTCGTTAGTTTCTTGTTAAACATTTTCTTAGTCCAGTTTTTCTCGCTTATTGGGTTTAATATTCTTCTTGAAAATAGTCGATGCTATGTTATCTATAACTTTTCTAATAAAA TTGTGTTTCAAGCTCTAAAAAA

Fig. 2. Sequence of cDNA encoding PW29 and deduced protein sequence. $*$, putative initiation site; $\star$, potential N-glycosylation sites; - , a segment composed of basic and acidic amino acid residues; $=$, pentaproline motif; $=$, polyadenylation signals. GenBank accession number is D49429. 
same membrane was stained with Amino Black as described before (12).

Detection of $P W 29$ by antibodies against a fusion protein produced by MBP. Purified GST fusion protein $(300 \mu \mathrm{g})$ was dialysed against $0.5 \mathrm{M} \mathrm{NaCl}, 0.1 \mathrm{M} \mathrm{NaHCO}$ (pH 8.0) and coupled to the $\mathrm{CNBr}$-activated Sepharose $4 \mathrm{~B}(0.5 \mathrm{ml})$ according to the method of the manufacturer, Two $\mathrm{ml}$ of antiMBP-PW29 antiserum was applied to a column containing the fusion protein-Sepharose. Antibodies bound to the column were eluted with $0.1 \mathrm{M}$ glycine- $\mathrm{HCl}(\mathrm{pH} 2.5)$ and immediately neutralized with Tris- $\mathrm{HCl}, \mathrm{pH}$ 8.8. Immunoblot analysis was carried out after F9 cells were separated by SDS-polyacrylamide gel electrophoresis on a $10 \%$ gel and transferred to the nitrocellulose membrane as described before (11). Antibodies eluted from a column containing GST-Sepharose were used as a control.

\section{RESULTS AND DISCUSSION}

Cloning and sequence analysis of PW29. A Agt11 expression library constructed from F9 embryonal carcinoma cells was screened by antibodies against pokeweed agglutinin (PWA)-binding glyco-proteins isolated from

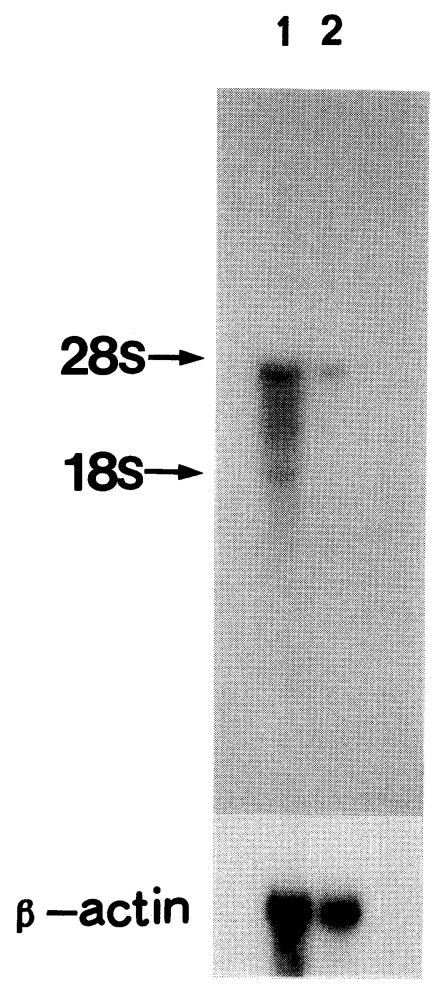

Fig. 3. Expression of PW 29 mRNA in F9 and PYS-2 cells. Poly(A) ${ }^{+}$RNAs $(10 \mu \mathrm{g})$ were denatured, separated by $1 \%$ agarose gel electrophoresis, transferred to a nitrocellulose membrane and hybridized with an $\left[\alpha-{ }^{32} \mathrm{P}\right] \mathrm{dCTP}-\mathrm{labeled}$ probe (BamHI-EcoRI restriction fragment of PW29 cDNA). 1) F9 cells and 2) PYS-2 cells. Lower lane: hybridization with $\beta$-actin probe. these cells. Three positive clones were obtained. Analysis by restriction endonucleases and Southern blotting revealed that the 3 clones were independent. Thus, we analyzed one of the clones, PW29 in detail. One of the other clones, PW19, encoded a calcium binding protein structurally unrelated to PW29 protein (10).

By Northern blot analysis, the PW29 probe (XhoI/ EcoRI fragment of PW29) detected a single band of 4.3 kb. Since PW29 insert was about 3 kb (Fig. 1, 2), we analyzed the $5^{\prime}$ end sequences by screening $\lambda \mathrm{gt} 10 \mathrm{cDNA}$ library constructed from F9 cells using PW29 probe (EcoRI-XhoI fragment of PW29). We got the clone PW29-16 and could extend the sequence about $0.9 \mathrm{~kb}$ (Fig. 1, 2). Thus, PW29 and PW29-16 yielded composite DNA sequence of $3.9 \mathrm{~kb}$ (Fig. 1, 2). This sequence comprised $84 \%$ of the size of PW29 mRNA in F9 cells (Fig. 3).

Sequencing data showed a single open reading frame, extending from the ATG at nucleotide 567 to the TGA stop codon at base 2486 encoding a polypeptide with a predicted molecular weight of $70 \mathrm{kD}$. The sequence has
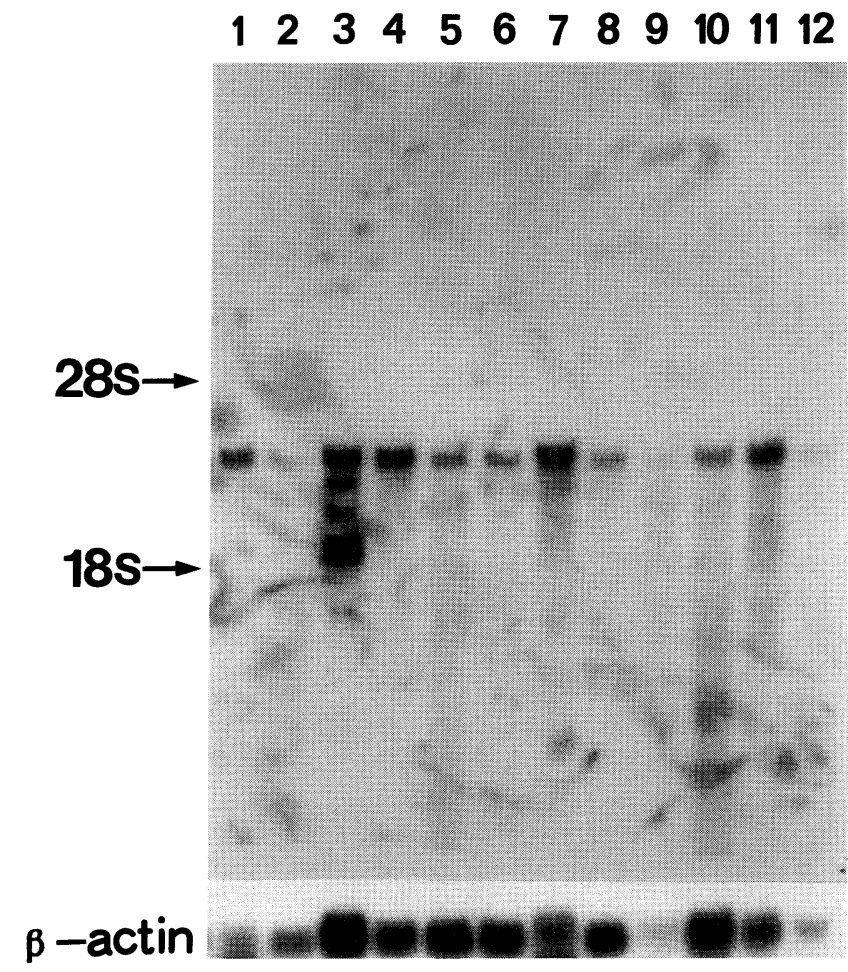

Fig. 4. Expression of PW29 mRNA in different tissues from adult Mice. Twenty $\mu \mathrm{g}$ of the total RNAs were denatured, separated by $1 \%$ agarose gel electrophoresis, transferred to a nitrocellulose membrane and hybridized with an $\left[\alpha{ }^{-32} \mathrm{P}\right] \mathrm{dCTP}-$ labeled probe (BamHI-EcoRI restriction fragment of PW29 cDNA). 1) muscle, 2) colon, 3) testis, 4) brain, 5) spleen, 6) ovary, 7) heart, 8) stomach, 9) liver, 10) lung, 11) kidney and 12) small intestine. Lower lane: hybridization with $\beta$-actin probe. 
$(\text { Pro })_{2-5}$, (LysArg) $)_{2-3}$ and a long stretch of hydrophylic amino acids composed of (GluLys) $)_{5}(\mathrm{Glu})_{7}$ AspGluAsp. Although PW29 protein has no significant homology with other proteins, this feature of the protein has some resemblance to calreticulin, a calcium binding protein, which has a proline rich segment and C-terminal segments rich in poly-acidic amino acids (1). We also note that the proline cluster is present in the cytoplasmic portion of Fas ligand (15), and that pentaproline structure present in PW29 protein conforms to the consensus sequence for the binding site of Src-homology region III (16). The consensus motif is p $\Phi \mathrm{PpXP}$ (P represents proline, $p$ represents residues that tend to be proline, $\Phi$ represents hydrophobic residues and $\mathrm{X}$ represents nonconserved residues). This observation raised a possibility that PW29 protein is involved in intracellular signal transduction system.

Northern blot experiment indicated that PW29

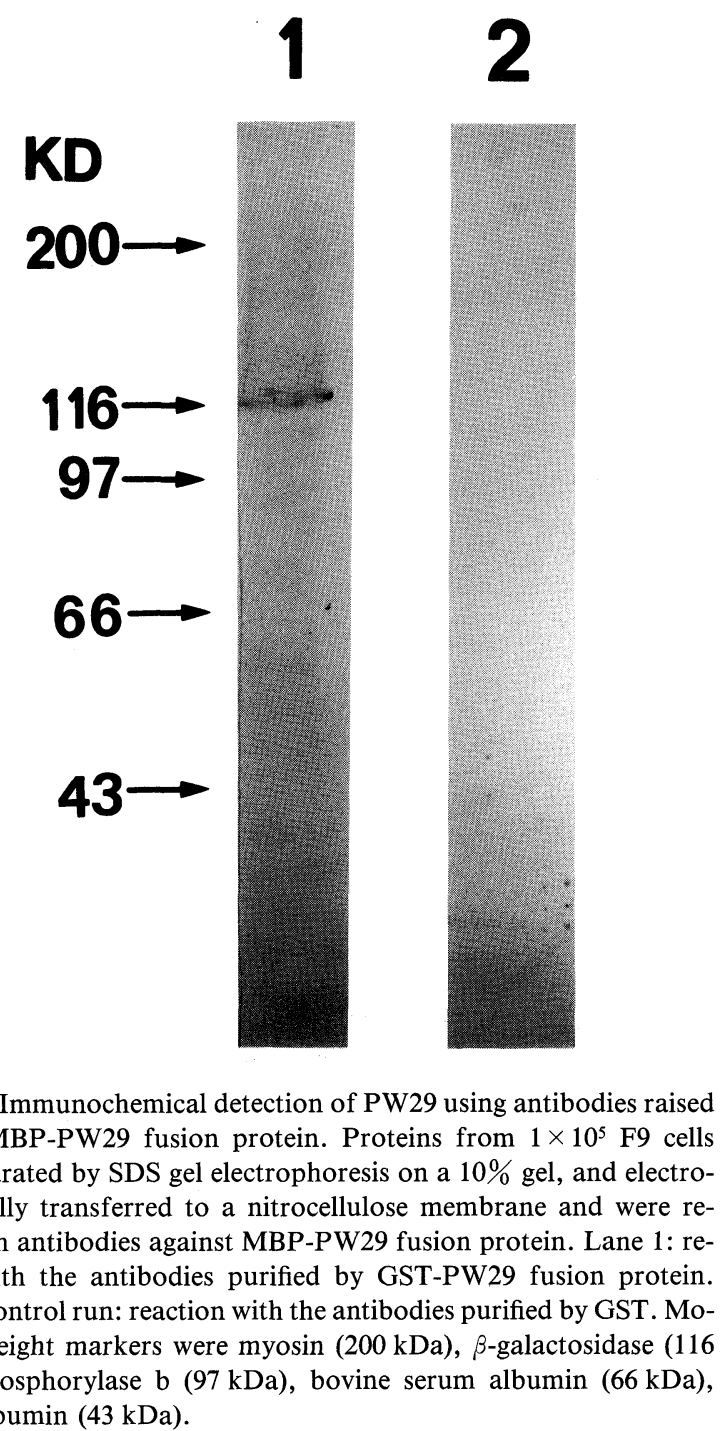

mRNA was strongly expressed in the testis, brain, kidney and heart of adult mice (Fig. 4) as well as in F9 cells (Fig. 3). The size of the mRNA was heterogeneous. In PYS-2 cells, which represent parietal endoderm cells differentiated from F9 cells, the PW29 mRNA was only weakly expressed (Fig. 3).

PWA binding sites comprise many glycoproteins of different molecular weights. We examined what molecular species corresponded to the protein specified by the cDNA clone. For that purpose, we isolated the MBPPW29 fusion protein and immunized it to a rabbit. F9 cells were separated by SDS gel electrophoresis, transferred to nitrocellulose membranes, and stained with antifusion protein anti-serum which was purified by GST fusion protein coupled to $\mathrm{CNBr}$-activated Sepharose 4B. We detected a band of apparent molecular weight 120 $\mathrm{kDa}$ (Fig. 5); this band was not detectable upon Western blotting using a control antibody purified by GST column. The difference of the predicted molecular weight $(70 \mathrm{kDa})$ and the observed molecular weight de-

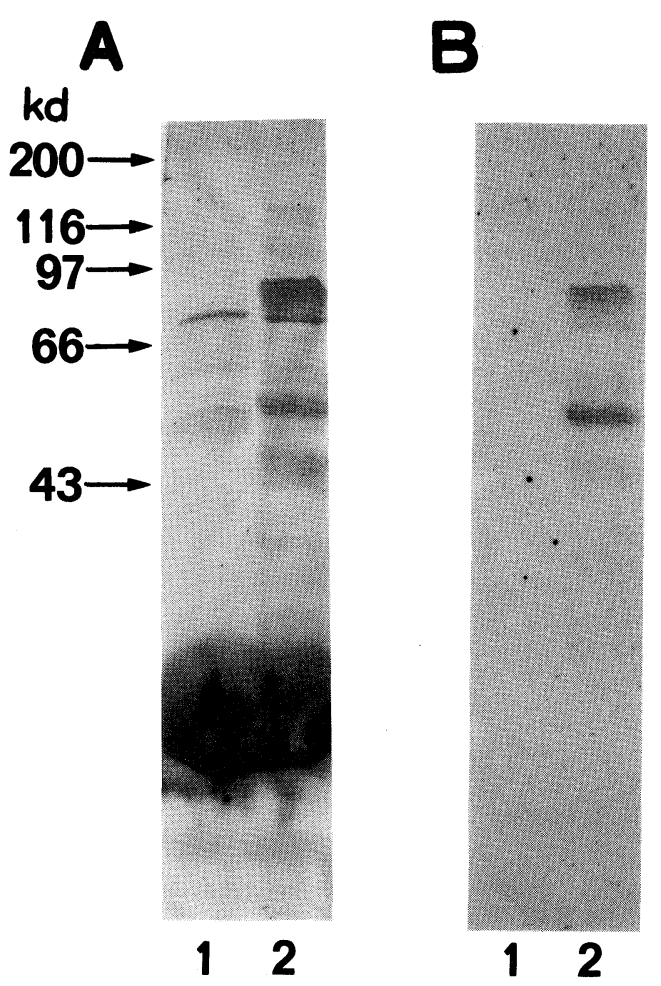

Fig. 6. Calcium blotting analysis. Glutathione-S-transferase $(5 \mu \mathrm{g})$ (lane 1) and glutathione-S-transferase-PW29 fusion protein $(5 \mu \mathrm{g})$ (lane 2) purified on glutathione agarose column were electrophoresed and transferred to a nitrocellulose membrane. After incubation with $\mathrm{Ca}^{2+}$, the membrane was exposed to x-ray film (B). The same membrane was stained with Amino Black to detect proteins (A). GST migrated as a huge band of molecular weight $27.5 \mathrm{kDa}$. Because of the instability of the fusion protein, a large amount of GST was detected in the lane of the fusion protein (A, lane 2). 
tected upon SDS gel electrophoresis is best explained by unusual electrophoretic behavior due to the presence of highly charged segments in the polypeptide. Indeed, calreticulin which has a molecular weight $45.5 \mathrm{kDa}$ migrates as a $60 \mathrm{kDa}$ protein upon SDS-PAGE (1). However, the possibility is not excluded that the PW29 cDNA so far cloned represent a truncated minor component originated by alternative splicing.

Calcium binding property of PW29 protein. We examined whether PW29 protein can bind $\mathrm{Ca}^{2+}$. For that purpose, glutathione-S-transferase fusion protein was produced, and was purified by affinity chromatography on glutathion agarose column. The purified fusion protein, but not glutathione-S-transferase reacted with $\mathrm{Ca}^{2+}$ upon calcium blotting (Fig. 6). In addition to the $90 \mathrm{kDa}$ fusion protein band, a $55 \mathrm{kDa}$ band, which was considered to be partially degraded fusion protein, also reacted with calcium.

As above, PW29 is a calcium binding protein strongly expressed in several adult organs as well as in a line of embryonal carcinoma cells. Since the sequence lacks a signal sequence and a hydrophobic region, PW29 is likely to be a cytoplasmic protein. However, PW29 as well as endoplasmic reticulum resident calcium binding protein CBP-140 (10) were cloned by using antibodies to teratocarcinoma glycoproteins purified by PWA lectin. By using antibodies to teratocarcinoma glycoproteins, which were isolated by affinity chromatography on another lectin, Dolichos biflorus agglutinin (DBA), we also cloned reticulocalbin, a calcium binding protein principally located in the luminal side of the endoplasmic reticulum (12). It is possible that these calcium binding proteins are bound to the cytoplasmic region of the membrane glycoproteins, and that after detergent solubilization and lectin affinity chromatography, the calcium binding protein co-purifies with membrane glycoproteins. Furthermore, we noted that the PW-29 $c D N A$ sequence is almost identical to a galactosyltransferaserelated antigen isolated in our laboratory (Uehara and Muramatsu, unpublished results). Since this antigen expressed in $E$. coli did not express enzyme activity, we considered that $\mathrm{PW}-29$ is a calcium binding protein and antibodies against the enzyme reacted with PW-29 by antigenic cross reactivity. In any event, a novel calcium binding protein, PW29, is an interesting molecule for further study, because of its possible role in cell regulation.

Acknowledgments. This work was supported in part by grants from the Ministry of Education, Science and Culture of Japan. We thank Kumiko Sato for her expert secretarial assistance.

\section{REFERENCES}

1. BaKsh, S. and MichalaK, K. 1991. Expression of calreticulin in Escherichia coli and identification of its $\mathrm{Ca}^{2+}$ binding domains. J. Biol. Chem., 266: 21458-21465.

2. Benton, W.D. and Davis, R.W. 1977. Screening $\lambda$ gt recombinant clones by hybridization to single plaques in situ. Science, 196: $180-182$.

3. Chomczynski, P. and SACCHI, N. 1987. Single-step method of RNA isolation by acid guanidinium thiocyanate-phenol-chloroform extraction. Analytical Biochemistry, 162: 156-159.

4. Heizmann, C.W. and Henziker, W. 1991. Intracellular calcium-binding proteins: more sites than insights. Trends Biochem. Sci., 16: 98-103.

5. KRETSINGER, R.H. 1980. Structure and evolution of calciummodulated proteins. CRC Crit. Rev. Biochem., 8: 119-174.

6. Maniatis, T., Frisch, E.F., and Sambrook, J. 1982. In Molecular cloning (Maniatis, T., Frisch, E.F., and Sambrook, J., eds.). Cold Spring Harbor Laboratory, Cold Spring Harbor, New York, pp 371-372.

7. Milner, R.E., Baksh, S., Shemanko, C., Carpenter, M.R., Smillie, L., Vance, J.E., Opas, M., and Michalak, M. 1991. Calreticulin, and not calsequestrin, is the major calcium binding protein of smooth muscle sarcoplasmic reticulum and liver endoplasmic reticulum. J. Biol. Chem., 266: 7155-7165.

8. Miyauchi, T., Kanekura, T., Yamaoka, A., Ozawa, M., Mryazawa, S., and Muramatsu, T. 1990 . Basigin, a new broadly distributed member of the immunoglobulin superfamily, has strong homology with both the immuno-globulin V domain and the $\beta$-chain of major histocompatibility complex class II antigen. J. Biochem., 107: 316-323.

9. Muramatsu, H. and Muramatsu, T. 1990. Analysis of glycoprotein-bound carbohydrates from pluripotent embryonal carcinoma cells by pokeweed agglutinin-agarose. J. Biochem., 107: 629-634.

10. Naved, A.F., Ozawa, M., Yu, S., Miyauchi, T., Muramatsu, H., and Muramatsu, T. 1995. CBP-140, a novel endoplasmic reticulum resident $\mathrm{Ca}^{2+}$-binding protein with a carboxy-terminal NDEL sequence showed partial homology with $70 \mathrm{kDa}$ heat shock protein (hsp 70). Cell Struct. Funct., 20: 133-141.

11. Ozawa, M., BaAribault, H., and Kemler, R. 1989. The cytolasmic domain of the cell adhesion molecule uvomorulin associates with three independent proteins structurally related in different species. EMBO J., 8: 1711-1717.

12. Ozawa, M. and Muramatsu, T. 1993. Reticulocalbin, a novel endoplasmic reticulum resident $\mathrm{Ca}^{2+}$-binding protein with multiple EF-hand motifs and a carboxy-terminal HDEL sequence. $J$. Biol. Chem., 268: 699-705.

13. SANGer, F., Nicklen, S., and Coulsen, A.R. 1977. DNA sequencing with chain-terminating inhibitors. Proc. Natl. Acad. Sci. USA, 74: 5463-5467.

14. Schuh, R., Vestweber, D., Riede, I., Ringwald, M., Rosenberg, U.B., Tackle, H., and Kemler, R. 1986. Molecular cloning of the mouse cell adhesion molecule uvomorulin: cDNA contains a B1-related sequence. Proc. Natl. Acad. Sci. USA, 83: 1364-1368.

15. Suda, T., Takahashi, T., Golstein, P., and Nagata, S. 1993. Molecular cloning and expression of the Fas ligand, a norval member of the tumor necrosis factor family. Cell, 75: $1169-1178$.

16. Yu, H., Chen, J.K., Feng, S., Dalgarno, D.C., Brauer, A.W., and Schreiber, S.L. 1994. Structural basis for the binding of prolinerich peptides to SH3 domains. Cell, 76: 933945.

(Received for publication, May 17, 1995

and in revised form, May 25, 1995) 